Aims and Scope The Journal of the International Neuropsychological Society is the official journal of the International Neuropsychological Society, an organization of over 4,500 international members from a variety of disciplines. The Journal of the International Neuropsychological Society welcomes original, creative, high quality research papers covering all areas of neuropsychology. The focus of articles may be primarily experimental, applied, or clinical. Contributions will broadly reflect the interest of all areas of neuropsychology, including but not limited to: development of cognitive processes, brain-behavior relationships, adult and pediatric neuropsychology, neurobehavioral syndromes (such as aphasia or apraxia), and the interfaces of neuropsychology with related areas such as behavioral neurology, neuropsychiatry, genetics, and cognitive neuroscience. Papers that utilize behavioral, neuroimaging, and electrophysiological measures are appropriate.

To assure maximum flexibility and to promote diverse mechanisms of scholarly communication, the following formats are available in addition to Regular Research Articles: Brief Communications are shorter research articles; Rapid Communications are intended for "fast breaking" new work that does not yet justify a full length article and are placed on a fast review track; Neurobehavioral Grand Rounds are theoretically important and unique case studies; Critical Reviews and Short Reviews are thoughtful considerations of topics of importance to neuropsychology, including associated areas, such as functional brain imaging, genetics, neuroepidemiology, and ethical issues; Dialogues provide a forum for publishing two distinct positions on controversial issues in a pointcounterpoint format; Symposia consist of several research articles linked thematically: Letters to the Editor respond to recent articles in the Journal of the International Neuropsychological Society; and Book Reviews. Critical Reviews, Dialogues, and Symposia are typically invited by the Editor-in-Chief or an Associate Editor. Book Reviews are considered but are no longer solicited.

Originality and Copyright To be considered for publication in the Journal of the International Neuropsychological Society, a manuscript cannot have been published previously nor can it be under review for publication elsewhere. Papers with multiple authors are reviewed with the assumption that all authors have approved the submitted manuscript and concur with its submission to the Journal of the International Neuropsychological Society. A Copyright Transfer Agreement, with certain specified rights reserved by the author, must be signed and returned to the Editor-in-Chief by the corresponding author of accepted manuscripts, prior to publication. This is necessary for the wide distribution of research findings and the protection of both author and the society under copyright law. If you plan to include material that has been published elsewhere and is under copyright of a third party, you will need to obtain permission to re-use this material in your article. A form may be provided for this purpose by the editorial office. Alternatively, many publishers use an online system for such requests. It is the responsibility of the authors to obtain permissions to re-use material from elsewhere. For information regarding rights and permissions concerning the Journal of the International Neuropsychological Society, please contact Marc Anderson (manderson@ cambridge.org) or Adam Hirschberg (ahirschberg@ cambridge.org).

Disclosure Potential conflicts of interest include funding sources for the reported study (e.g., a test validation study financially supported by a test publisher, a study supported by an insurance company), personal or family financial interest in a test or product or with a company that publishes a test that is being investigated in the manuscript or competes with a test that is being investigated in the manuscript. Other conflicts include employment, consultancies, stock ownership or medicolegal work. For the latter, information about whether the author's medicolegal work is largely for one side should be reported. This list of potential conflicts is not all inclusive, and it is the responsibility of each author to ensure that all of their "potential conflicts" are reported in the Acknowledgment section of the paper

Disclosure pertains to all authors. It is the corresponding author's ethical responsibility to explicitly check with each of his/her co-authors to ensure that any real or apparent conflict of interest is appropriately disclosed. Authors should err on the side of full disclosure, and if authors are uncertain about what constitutes a relevan conflict, they should contact the editorial office jins@cambridge.org. The intent of this disclosure is not to prevent an author with a significant financial or other relationship from publishing their work in the Journal of the International Neuropsychological Society, but rather to provide readers with adequate information to form their own judgments about the work.

Compliance with institutional research standards for animal or human research (including a statement that the research was completed in accordance with the Helsinki Declaration (http://www.wma.net/en/ 30publications/10policies/b3/) should be included in the methods section of the manuscript.

Manuscript Submission and Review The Journal of the International Neuropsychological Society uses online submission and peer review. Paper submissions are not accepted. Authors who are not able to submit their manuscripts online are asked to contact the editorial office at: jins@cambridge.org. The website address for submissions is http://mc.manuscriptcentral.com/cup/jins; complete instructions are provided on the website Prior to online submission, please consult http:// www.nlm.nih.gov/mesh/ for 6 keywords or mesh terms that are different from words in the title. Accurate mesh terms will increase the probability that your manuscript will be identified in online searches. Please follow the instructions carefully to avoid delays. The menu will prompt the author to provide all necessary information, including the manuscrip category, the corresponding author including postal address, phone and fax numbers, and e-mail address, and suggested reviewers.

The website will automatically acknowledge receipt of the manuscript and provide a manuscript reference number. The Editor-in-Chief will assign the manuscript for review to an action editor and at least two other reviewers. Every effort will be made to provide the author with a review within 6 to 10 weeks of manuscript assignment. Rapid Communications will be reviewed within 6 weeks. If the Editor requests that revisions be made to a manuscript before publication, a maximum of 3 months will be allowed for preparation of the revision, except in unusual circumstances.

Manuscript Length In order to increase the number of manuscripts that can be published in the Journal of the International Neuropsychological Society, please adhere to the following length requirements. Please provide a word count on the title page for the abstract and manuscript (not including abstract, tables, figures, or references). Manuscripts will be returned if they exceed length requirements
Regular Research Article: Maximum of 5,000 words (not including abstract, tables, figures, or references) and a 250 word abstract. Regular Research Articles are original, creative, high quality papers covering all areas of neuropsychology; focus may be experimental, applied or clinical.

Brief and Rapid Communications: Maximum of 2,500 words (not including abstract, tables, figures, or references) and a 200 word abstract, with a maximum of two tables or two figures, or one table and one figure, and 20 references. Brief and Rapid Communications are shorter research articles.

Case Reports: Maximum of 3,500 words with an informative literature review (not including abstract, tables, figures, or references) and a 200 word abstract. Unique case studies that make a significant theoretical contribution.

Critical Review: Maximum of 7,000 words (not including abstract, tables, figures, or references) and a 250 word abstract. Critical Reviews will be considered on any important topic in neuropsychology. Quantitative meta-analyses are encouraged. Critical Reviews must be preapproved by the Editor-in-Chief. For consideration, please e-mail your abstract to jins@ cambridge.org.

Short Review: Maximum of 2,500 words (not including abstract, tables, figures, or references) and a 150 word abstract. Short Reviews are conceptuallyoriented snapshots of the current state of a research area by experts in that area. Short Reviews must be preapproved by the Editor-in-Chief. For consideration, please e-mail your abstract to jins@ cambridge. org.

Dialogues: Maximum of 2,000 words for each segment (not including abstract, tables, figures, or references) and a 150 word abstract, with a maximum of two tables or two figures, or one table and one figure and 20 references. Dialogues provide a forum for two distinct positions on controversial issues in a point-counterpoint form. Dialogues must be preapproved by the Editor-in-Chief. For consideration, please e-mail your abstract to jins @ cambridge.org.

Symposia: Maximum of 5,000 words (not including abstract, tables, figures, or references) and a 250 word abstract for each article (same as Regular Research Articles). Symposia consist of several thematically linked research articles which present empirical data. Symposia must be pre-approved by the Editorin-Chief. For consideration, e-mail your proposal to jins@cambridge.org to receive prior approval.

Letters to the Editor: Maximum of 500 words (not including table, figure, or references) with up to five references and one table or one figure. Letters to the Editor respond to recent articles in Journal of the International Neuropsychological Society.

Book Reviews: Maximum of 1000 words in length. Include name and affiliations, a title for the review, the author(s)/editor(s), title, publisher, date of publication, number of pages and price. For consideration, e-mail jins@cambridge.org.

Manuscript Preparation and Style The entire manuscript should be typed double-spaced throughout using a word processing program. Unless otherwise specified, the guideline for preparation of manuscripts is the Publication Manual of the American Psychological Association (6th edition) except for references with 3 or more authors (see References section). This manual may be ordered 
from: APA Order Dept., 750 1st St. NE, Washington, DC 20002-4242, USA.

Pages should be numbered sequentially beginning with the Title Page. The Title Page should contain the full title of the manuscript, the full names and institutional affiliations of all authors; mailing address, telephone and fax numbers, and e-mail address for the corresponding author; and the word count for the abstract and manuscript text (excluding title page, abstract, references, tables, and figures). At the top right provide a short title of up to 45 characters preceded by the lead author's last name. Example: Smith-Memory in Parkinson's Disease. This running head should be repeated at the top right of every following page.

Page 2 should include an Abstract and a list of at least six keywords or mesh terms. Note: structured abstracts must be included with papers submitted after January 1, 2014. A structured abstract must include four header labels: Objective, Method, Results, and Conclusions. A total of six mesh terms (http://www.nlm.nih.gov/mesh/) or keywords should be provided and should not duplicate words in the title.

The full text of the manuscript should begin on page 3. For scientific articles, including Regular Research Articles, Brief Communications, Rapid Communications, and Symposia, the format should include a structured Abstract, Introduction, Method, Results, and Discussion. This should be followed by Acknowledgments, References, Tables, Figure Legends, Figures, and optional Appendices and Supplemental Material.

The use of abbreviations, except those that are widely used, is strongly discouraged. They should be used only if they contribute to better comprehension of the manuscript. Acronyms should be spelled out at first mention. Metric system (SI) units should be used.

Appendices and Supplemental Materials may be submitted. Appendices include material intended for print and should be included with the manuscript file. Supplementary material will appear only online and should be submitted as a separate file.

The Acknowledgements Section should include a disclosure of confiicts of interest (see above) and all sources of financial support for the paper. In documenting financial support, please provide details of the sources of financial support for all authors, including grant numbers. For example, "This work was supported by the National Institutes of Health (grant number XXXXXXX)". Multiple grant numbers should be separated by a comma and space and where research was funded by more than one agency, the different agencies should be separated by a semicolon with "and" before the final funding agency. Grants held by different authors should be identified using the authors' initials. For example, "This work was supported by the Wellcome Trust (A.B., grant numbers XXXX, YYYY), (C.D., grant number ZZZZ); the Natural Environment Research Council (E.F., grant number FFFF); and the National Institutes of Health (A.B., grant number GGGG), (E.F., grant number $\mathrm{HHHH}) . "$

Tables and Figures should be numbered in Arabic numerals. Figures should be numbered consecutively as they appear in the text. Figures should be twice their intended final size and authors should do their best to construct figures with notation and data points of sufficient size to permit legible photo reduction to one column of a two-column format.

Please upload figure(s) in either a .doc or .pdf format There is no additional cost for publishing color figures. When uploading figures (color or black and white) they need only be a high enough resolution for the reviewers and editors to identify the information you are trying to convey.

The approximate position of each table and figure should be provided in the manuscript: [INSERT TABLE 1 HERE]. Tables and figures should be on separate pages. Tables should have short titles and all figure legends should be on separate pages.

References should be consistent with the Publication Manual of the American Psychological Association (6th Edition). In-text references should be cited as follows: ". . . Given the critical role of the prefrontal cortex (PFC) in working memory (Cohen et al., 1997; Goldman-Rakic, 1987; Perlstein et al., 2003a, 2003b) . . ." with multiple references in alphabetical order. Another example: “...Cohen et al. (1994, 1997), Braver et al. (1997), and Jonides and Smith (1997) demonstrated ..."' References cited in the text with two authors should list both names. References cited in the text with three, four, or five authors, list all authors at first mention; with subsequent citations, include only the first author's last name followed by et al. References cited in the text with six or more authors should list the first author et al. throughout. In the reference section, for works with up to seven authors, list all authors. For eight authors or more, list the first six, then ellipses followed by the last author's name. Examples of the APA reference style are as follows:

Online/Electronic Journal Article with DOI:

Dikmen, S., Machamer, J., Fann, J. \& Temkin, N. (2010). Rates of symptom reporting following traumatic brain injury. Journal of the International Neuropsychological Society, 16, 401-411. doi:10.1017/ S1355617710000196

\section{Scientific Article:}

Giovannetti, T., Britnell, P., Brennan, 1., Siderowf, A., Grossman, M., Libon, D.J., Seidel, G.A. (2012). Everyday action impairment in Parkinson's disease dementia.
Journal of the International Neuropsychological Society, 18, 787-798.

Book:

Lezak, M.D., Howieson, D.B., Bigler, E.D., Tranel, D. (2012). Neuropsychological Assessment. New York: Oxford University Press.

\section{Book Chapter:}

Mahone, E.M. \& Slomine, B.S. (2008). Neurodevelopmental disorders. In J.E. Morgan, \& J.H. Ricker (Eds.), Textbook of Clinical Neuropsychology (pp. 105-127). New York: Taylor \& Francis.

Report at a Scientific Meeting:

Weintraub, S. (2012, June). Profiles of dementia: Neuropsychological, neuroanatomical and neuropathologic phenotypes. International Neuropsychological Society, Oslo, Norway.

Manual, Diagnostic Scheme, etc.:

American Psychiatric Association (1994). Diagnostic and Statistical Manual of Mental Disorders ( $4^{\text {th }}$ ed.). Washington, DC: American Psychiatric Association Press.

English Editing The Research and Editing Consulting Program (RECP) within the International Neuropsychological Society's International Liaison Committee is designed to provide English language editing and statistical consulting to international colleagues who wish to publish their research in English language journals. For additional information see http:// www.the-ins.org/the-research-and-editing-consultingprogram.

Proofs The publisher reserves the right to copyedit manuscripts. The corresponding author will receive PDFs for final proofreading. These should be checked and corrections returned within 2 days of receipt. The publisher reserves the right to charge authors for excessive corrections.

Offprints and PDF Files The corresponding author will receive a free pdf. This pdf can also be mounted on the authors' web pages. Offprints must be ordered when page proofs are returned. The offprint order form with the price list will be sent with your PDF.

Open Access Papers In consideration of payment of the Open Access fee specified by Cambridge University Press, the contribution will be published in the Journal of the International Neuropsychological Society within an Open Access environment, freely accessible to those who wish to browse, read, print, save, copy, display or further disseminate the contribution. Please see the Open Access Transfer of Copyright Agreement for the proper procedures at http://journals.cambridge.org/action/displayMoreInfo? jid=INS\&type $=t c r$. The processes will depend on your source of funding, permissions to use material owned by an outside source, etc. 


\section{Discover the benefits of JDOHaD on Cambridge Journals Online (CJO)}

- Register for content alerts and receive notification when new articles are published online journals.cambridge.org/doh-alerts

- Save searches

- Search across Cambridge Books Online (CBO) and Cambridge Journals Online (CJO) simultaneously using our new faceted search functionality

- Register for updates on new developments and sample content from your 'favourite journals'

- Easily download citations to reference management software

- Access CJO on your mobile: CJOm is optimised for smart phones and other small mobile devices

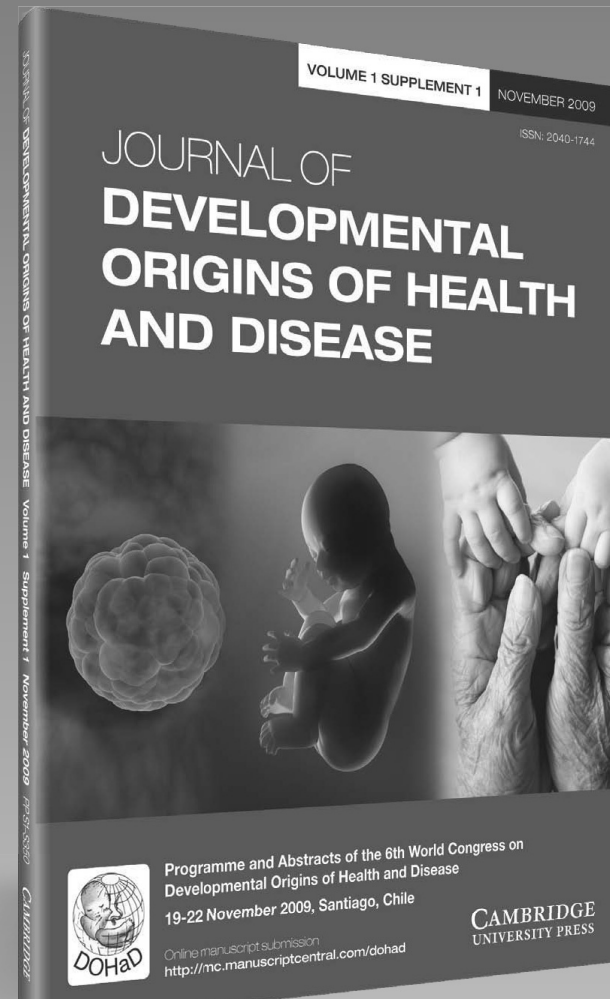

Members of $\mathrm{DOHaD}$ receive free access to the Journal.

If you have any problems setting up your online access please contact:

journals_societies@cambridge.org

\section{Submit your research to JDOHaD}

The Journal covers all aspects of research in developmental origins of health and disease (DOHaD) - from basic molecular research to health and disease outcomes, translation into policy and wider social and ethical issues.

- Global Editorial Board

- Dissemination of your research to over 5,000 libraries worldwide, including access through aid donation schemes

- Efficient online manuscript submission and tracking at ScholarOne ${ }^{\mathrm{TM}}$ Manuscripts

- FirstView publication of articles online ahead of issue and print allocation

\section{mc.manuscriptcentral.com/dohad}

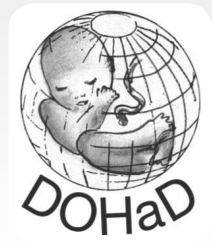

- Generous copyright policies, compliant with all the major funding bodies

- State-of-the-art online hosting

- Forward reference linking

- Permanent record through DOI/CrossRef

- No submission or page charges

- Authors receive a free pdf of the final article
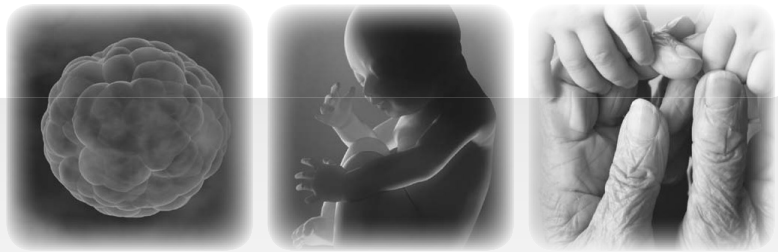


\section{CAMBRIDGE}

\section{JOURNALS}

\section{Brain}

\section{Impairment}

A Journal of the Australian Society for the Study of Brain Impairment (ASSBI)

\section{Editors}

Jennifer Fleming, University of Queensland, Australia

Grahame Simpson, Liverpool Brain Injury Rehabilitation Unit, Australia

A multidisciplinary Journal of the Australian Society for the Study of Brain Impairment. Topics covered include neurology, neuropsychology, psychiatry, clinical psychology, neuropathology, occupational therapy, physiotherapy, speech pathology and anatomy. Submissions are welcome across the full range of conditions that affect brain function (stroke, tumour, dementing illnesses, traumatic brain injury, epilepsy etc.) throughout the lifespan.

\section{To subscribe contact} Customer Services

\section{in Cambridge:}

Phone +44 (0)1223 326070

Fax $+44(0) 1223325150$

Email journals@cambridge.org

in New York:

Phone +1 (845) 3537500

Fax +1 (845) 3534141

Email

subscriptions_newyork@cambridge.org

\section{Free email alerts}

Keep up-to-date with new material - sign up at

journals.cambridge.org/bim-alerts 


\section{CAMBRIDGE}

\section{JOURNALS}

\section{CNS Spectrums}

\section{Editor-in-Chief}

Stephen M. Stahl, University of California San Diego, School of Medicine, USA

CNS Spectrums aims to be the premier journal covering all aspects of clinical neurosciences, neurotherapeutics and neuropsychopharmacology, particularly those pertinent to the clinician and clinical investigator. The journal, now bimonthly, features focused, in-depth, illustrated, readable reviews, commentaries, and original research articles. New therapeutics of all types in psychiatry, mental health, and neurology are emphasized, especially first in studies on humans and proof of concept studies. Subject coverage spans the full spectrum of neuropsychiatry, focusing on translational issues and those crossing traditional boundaries between neurology and psychiatry.

To subscribe contact Customer Services

\section{in Cambridge:}

Phone $+44(0) 1223326070$

Fax $+44(0) 1223325150$

Email journals@cambridge.org

in New York:

Phone +1 (845) 3537500

Fax +1 (845) 3534141

Email

subscriptions_newyork@cambridge.org

\section{Free email alerts}

Keep up-to-date with new material - sign up at

journals.cambridge.org/cns-alerts 


\section{Development and Psychopathology}

Editor

Dante Cicchetti, Mt. Hope Family Center, University of Rochester and Institute of Child Development and Department of Psychiatry, University of Minnesota, USA

This multi-disciplinary journal is devoted to the publication of original, empirical, theoretical and review papers which address the inter-relationship of normal and pathological development in adults and children. It is intended to serve the field of developmental psychopathology, which strives to understand patterns of adaptation and maladaptation throughout the lifespan. This journal is of interest to psychologists, psychiatrists, social scientists, neuroscientists, paediatricians and researchers.

To subscribe contact Customer Services

\section{in Cambridge:}

Phone $+44(0) 1223326070$

Fax $+44(0) 1223325150$

Email journals@cambridge.org

in New York:

Phone +1 (845) 3537500

Fax +1 (845) 3534141

Email

subscriptions_newyork@cambridge.org

\section{Free email alerts}

Keep up-to-date with new material - sign up at journals.cambridge.org/register 


\section{Journal of the International Neuropsychological Society}

Publishing, Advertising, Subscription Offices, and Indexing: Cambridge University Press, 32 Avenue of the Americas, New York, NY 10013-2473. Telephone: (212) 337-5000; Fax (212) 337-5959. Outside the USA, Canada, and Mexico: Cambridge University Press, The Edinburgh Building, Shaftesbury Road, Cambridge CB2 8RU, England (Telephone: 144(0) 1223 312-393; Fax: 144(0)1223 315-052. For advertising rates and data, contact the Journals Advertising Coordinator at the appropriate Cambridge University Press office. The Journal of the International Neuropsychological Society is covered by the major abstracting and indexing services, including Index Medicus, ISI Current Contents/Clinical Medicine, PubMed, Science Citation Index, SciSearch (also known as the Science Citation Index-expanded), Research Alert, the Neuroscience Citation Index, and PsycInfo.

Subscription Information: Published ten times a year: January, February, March, April, May, July, August, September, October and November. Annual institutional print and electronic subscription rates: US \$1,080.00 in the USA, Canada, and Mexico; UK £618.00 + VAT elsewhere. Institutional electronic rates only: US \$756.00 in the USA, Canada, and Mexico; UK $£ 454.00+$ VAT elsewhere. Print Only subscription no longer available in 2014 for Institutions. Please order bundle if print is required. Individual print rates only: US \$261.00 in the USA, Canada, and Mexico; UK £145.00 + VAT elsewhere. Single part rates: US \$99.00 in the USA, Canada, and Mexico; UK £57.00 + VAT elsewhere. Prices include surface postage and insurance.

Member Subscription: The Journal of the International Neuropsychological Society is an official publication of The International Neuropsychological Society. Members of the Society automatically receive the Journal of the International Neuropsychological Society as part of their annual membership dues. For further information on membership, please visit the INS website http://www.the-ins.org. INS office contact: Gordon J. Chelune, Ph.D., Executive Secretary, International Neuropsychological Society, 2319 South Foothill Drive \#260, Salt Lake City, UT 84109. E-mail: INS@utah.edu; Telephone: (801) 487-0475.

Information on Journal of the International Neuropsychological Society and all other Cambridge journals is available via http://www.cambridge.org/ in North America and in the UK. Full text for this journal can be found at http://journals.cambridge.org/

\section{Copyright $\odot 2015$ The International Neuropsychological Society}

All rights reserved. No part of this publication may be reproduced, in any form or by any means, electronic, photocopying or otherwise, without permission in writing from Cambridge University Press, except when permission is obtained through a bona fide copyright clearinghouse, such as the Copyright Clearance Center (USA) or the Copyright Licensing Agency (UK). For further information please visit http://us.cambridge.org/information/rights/ or http://www. cambridge.org/uk/information/rights/. The CCC Item-Fee Code for this publication is 1355-6177/13 \$25.00. Specific written permission must be obtained for all other copying. Photocopying for Classroom Use: Permission to reproduce parts of this publication for course anthologies may be obtained directly from Cambridge University Press or through duly authorized services such as the Academic Permissions Service of the CCC, 222 Rosewood Drive, Danvers, MA 01923 and the Copyright Permissions Service of the National Association of College Stores, or through any photoduplication service that properly secures permission from Cambridge or the CCC.

Periodicals postage paid at New York, NY, and additional mailing offices. Return Postage Guaranteed. Postmaster: Send address changes in the USA and Canada to: Journal of the International Neuropsychological Society, Cambridge University Press, Journals Fulfillment Dept., 100 Brook Hill Drive, West Nyack, NY 10994-2133.

Printed in the United States of America.

This publication is printed on acid-free paper. 


\title{
Journal of the International Neuropsychological Society
}

\author{
VOLUME 21
}

NUMBER 6

JULY 2015

\section{RESEARCH ARTICLES}

Striatal and Pallidal Activation during Reward Modulated Movement Using a Translational Paradigm

412

Cognitive Predictors of Reasoning through Treatment Decisions in Patients with Newly Diagnosed Brain Metastases

419

Naturalistic Action Performance Distinguishes Amnestic Mild Cognitive Impairment from Healthy Aging

Neuropsychological Profiles Differ among the Three Variants of Primary Progressive Aphasia

36 Motivation and Social Cognition in Patients with Schizophrenia

Shared and Divergent Auditory and Tactile Processing in Children with Autism and Children with Sensory Processing Dysfunction Relative to Typically Developing Peers Associations between Verbal Learning Slope and Neuroimaging Markers across the Cognitive Aging Spectrum

\section{BRIEF COMMUNICATION}

468
Measuring Cognition in Bipolar Disorder with Psychosis Using the MATRICS Consensus Cognitive Battery

\begin{abstract}
A. Bischoff-Grethe, R.B. Buxton, M.P. Paulus, A.S. Fleisher, T.T. Yang, and G.G. Brown
\end{abstract}

A. Gerstenecker, K. Duff, K. Meneses, J.B. Fiveash, L.B. Nabors, and K.L. Triebel

D.A. Gold, N.W. Park, K.J. Murphy, and A.K. Troyer

A.M. Butts, M.M. Machulda, J.R. Duffy, E.A. Strand, J.L. Whitwell, and K.A. Josephs

G. Fervaha, I. Siddiqui, G. Foussias, O. Agid, and G. Remington

C. Demopoulos, A.N. Brandes-Aitken, S.S. Desai, S.S. Hill, A.D. Antovich, J. Harris, and E.J. Marco

K.A. Gifford, J.S. Phillips, L.R. Samuels, E.M. Lane, S.P. Bell, D. Liu, T.J. Hohman, R.R. Romano III, L.R. Fritzsche, Z. Lu, A.L. Jefferson, and for the Alzheimer's Disease Neuroimaging Initiative

S.H. Sperry, L.K. O'Connor, D. Öngür, B.M. Cohen, M.S. Keshavan, and K.E. Lewandowski 